\title{
SEJARAH DAN SISTEM PENDIDIKAN SEKOLAH LUAR BIASA BAGIAN A NEGERI DENPASAR BALI
}

\author{
I Nyoman Bayu Pramartha, S.Pd., M.Pd \\ Pendidikan Sejarah IKIP PGRI Bali \\ bayoebondol@yahoo.com
}

\begin{abstract}
Abstrak
Penelitian bertujuan untuk mengetahui latar belakang berdirinya sekolah luar biasa bagian A di Denpasar. Penelitian ini sepenuhnya mengacu pada metode yang telah disiapkan. Pendekatan penelitian yang digunakan yaitu deskriptif kualitatif. Penentuan informan dengan teknik purposive sampling dan dikembangkan dengan teknik snow ball. Pengumpulan data melalui observasi, wawancara dan pencatatan dokumen. Hasil penelitian menunjukkan bahwa latar belakang berdirinya SLB/A Negeri Denpasar disebabkan anak-anak cacat khususnya anak tunanetra. Khususnya anak tunanetra yang belum mendapatkan pendidikan. Sistem pendidikan yang berlaku di SLB/A Negeri Denpasar, Bali meliputi: Kurikulum, tujuan pendidikan, pembelajaran evaluasi, pendidikan, siswa, alat pendidikan dan hasil didikan. Semua unsur ini bersinergi sebagai suatu kesatuan dalam rangka mewujudkan visi dan misi SLB/A Negeri Denpasar mewujudkan pendidikan yang professional dan bermutu bagi anak yang berkebutuhan khusus.
\end{abstract}

Kata Kunci: Sejarah sekolah luar bisa, sistem pendidikan sekolah luar biasa

\section{Abstract}

The research aims to determine: (1) Background The establishment of the School of Extraordinary Part A Denpasar. This study is fully refers to the method that has been prepared. The approach used in this study is qualitative descriptive. Determination of the informant by purposive sampling technique and developed with a snow ball technique. The collection of data through observation, interview and record-keeping. The results showed that the background of the establishment of SLB/A Negeri Denpasar caused by children with disabilities, especially blind children. Especially blind children are not getting an education. The education system in force in SLB/A Negeri Denpasar, Bali include: curriculum, educational goals, learning evaluation, education, students, educational tools and nurtured. All of these elements work together as a unit in order to realize the vision and mission of SLB/A Negeri Denpasar realize that professional and quality education for children with special needs.

Keywords: history of School of Extraordinary, the School of extraordinary system

\section{PENDAHULUAN}

\section{Pendidikan merupakan usaha}

manusia untuk membina kepribadian sesuai dengan nilai-nilai di masyarakat atau sebagai upaya membantu peserta didik untuk mengembangkan dan meningkatkan pengetahuan, kecakapan, nilai, sikap dan pola tingkah laku yang berguna bagi hidup. Pendidikan adalah memanusiakan manusia muda. Pendidikan bukanlah menghilangkan harkat dan martabat sebagai manusia, melainkan menumbuhkan dan mempertinggi mutu dan hakekat serta martabat manusia. Oleh karena itu pendidikan sifatnya mempengaruhi bukan menghilangkan, sebab tidak ada yang hilang dalam proses pendidikan. Hanya sifatnya mempengaruhi hal-hal yang kurang baik ke arah yang baik dan memperkembangkan potensi yang positif menjadi maksimal sesuai dengan potensinya (Suyasa, 1996:13-14). 
Pendidikan berkaitan dengan transmisi pengetahuan, sikap, kepercayaan, keterampilan dan aspekaspek kelakuan lainnya, kepada generasi yang lebih muda. Pendidikan merupakan suatu proses pembelajaran pola-pola kelakuan manusia menurut apa yang diharapkan oleh masyarakat. Asalkan pendidikan yang berlaku, harus tetap berpedoman berdasarkan pada Pancasila dan Undang-Undang Dasar Negara Republik Indonesia tahun 1945 yang berakar pada nilai-nilai agama, kebudayaan nasional Indonesia dan tanggap terhadap tuntutan perubahan zaman. Penelitian ini ingin mengkaji tentang pendidikan khusus, mengetahui sejarah pendidikan khusus dan sistem pendidikan dalam pendidikan khusus untuk anak cacat khususnya anak tunanetra.

Sekolah Luar Biasa adalah sebuah lembaga pendidikan formal yang melayani pendidikan bagi anak-anak berkebutuhan khusus. Sebagai lembaga pendidikan SLB dibentuk oleh banyak unsur yang diarahkan untuk mencapai tujuan pendidikan, yang proses intinya adalah pembelajaran bagi peserta didik. Jadi SLB merupakan lembaga pendidikan khusus yang menyelenggarakan program pendidikan bagi anak berkebutuhan khusus.

Dalam ketentuan umum UU Sisdiknas tahun 2003 pasal 1 ayat 1 dikemukakan bahwa: "Proses pembelajaran agar peserta didik secara aktif mengembangkan potensi dirinya, kecerdasan, akhlak mulia, serta keterampilan, yang diperlukan dirinya, masyarakat, bangsa dan Negara" (UU Sisdiknas, 2006:72). Bertitik tolak dari tujuan itulah setiap lembaga pendidikan termasuk di dalamnya Sekolah Luar Biasa hendaknya bergerak dari awal hingga akhir sampai titik tujuan suatu proses pendidikan, yang pada akhirnya dapat “mewujudkan terjadinya pembelajaran sebagai suatu proses aktualisasi potensi peserta didik menjadi kompetensi yang dapat dimanfaatkan atau digunakan dalam kehidupan" (Hari Suderadjat, 2005:6).

Syafaruddin

(2002:87)

mengemukakan bahwa: "Dalam sistem pendidikan nasional Indonesia sekolah memiliki peranan strategis sebagai institusi penyelenggara kegiatan pendidikan." Oleh karena itu, jelaslah bahwa Sekolah Luar Biasa memiliki dan mengemban tugas yang berat tetapi penting. Berat karena harus selalu berperang menghadapi berbagai kelemahan, ancaman dan tantangan guna menselaraskan program-program kegiatan yang terealisir dengan dinamika perkembangan ilmu pengetahuan dan teknologi (iptek) yang bergerak demikian cepat. Penting, karena tugas-tugas dan fungsi sekolah sangat diperlukan untuk mengembangkan potensi anak-anak berkebutuhan khusus demi kelangsungan hidupnya yang harus selalu dinamis dan optimis. 
Melihat kedudukan sekolah yang demikian pentingnya Syafaruddin (2002:88) mengatakan bahwa: "sekolah menjadi pusat dinamika masyarakat. Keberadaan sekolah menjadi institusi sosial yang menentukan pembinaan pribadi anak dan sosialisasi serta pembudayaan suatu bangsa." Di balik fungsi dan peranan sekolah yang sangat esensial bagi perkembangan pribadi peserta didik, masyarakat dan bangsa, serta tingginya harapan masyarakat terhadap sekolah ada satu realita yang masih jauh dari apa yang diharapkan oleh masyarakat. Dengan kata lain lembagalembaga sekolah masih berkualitas rendah dan belum dapat memenuhi harapan masyarakat. Hal itu tercermin dari rendahnya kualitas lulusan sekolah yang diekspresikan dengan menganggurnya siswa-siswa yang telah lulus sekolah. Bahkan dalam realita keseharian terlihat para lulusan yang belum dapat hidup mandiri untuk mengatasi persoalan kehidupannya sehari-hari. Hal ini sebagai cerminan masih rendahnya kualitas sumber daya manusia sebagai output pendidikan di Sekolah Luar Biasa. Hal itu dilatar belakangi karena siswa-siswi di SLB mempunyai IQ yang rendah di banding dengan anak-anak normal pada umumnya. Gambaran di atas sesuai dengan yang dikemukakan oleh Hari Suderadjat (2005:4) yang mengemukakan bahwa "lulusan sekolah khususnya di Indonesia dinilai bermutu rendah dalam komparasi Internasional".

Sejalan dengan pendapat Hari Suderajat dikemukakan pula tentang lemahnya mutu pendidikan kita oleh Syafaruddin (2002:19) sebagai berikut: dunia pendidikan kita belum sepenuhnya dapat memenuhi harapan masyarakat. Fenomena itu ditandai dari rendahnya mutu lulusan, penyelesaian masalah pendidikan yang tidak tuntas, atau cenderung tambal sulam, bahkan lebih orientasi projek. Akibatnya, seringkali hasil pendidikan mengecewakan masyarakat. Mereka terus mempertanyakan relevansi pendidikan dengan kebutuhan masyarakat dalam dinamika kehidupan ekonomi, politik, sosial, dan budaya. Kualitas lulusan pendidikan kurang sesuai dengan kebutuhan pasar tenaga kerja dan pembangunan, baik industri, perbankan, telekomunikasi, maupun pasar tenaga kerja sektor lainnya yang cenderung menggugat eksistensi sekolah. Bahkan SDM yang disiapkan melalui pendidikan sebagai generasi penerus belum sepenuhnya memuaskan bila dilihat dari segi akhlak, moral, dan jati diri bangsa dalam kemajemukan budaya bangsa.

Berangkat dari kenyataan di atas, maka harus dilakukan berbagai upaya untuk meningkatkan keberhasilan sekolah sehingga menjadi lembaga pendidikan yang efektif dan produktif. Terwujudnya Sekolah Luar Biasa yang efektif dan produktif merupakan suatu ciri bahwa 
sekolah itu berhasil dalam mengemban dan menjalankan tugas dan fungsinya. Sondng P. Siagian (dalam Syafaruddin, 2002:97) mengemukakan bahwa: “Organisasi yang berhasil adalah organisasi yang tingkat efektivitas dan produktivitasnya makin lama makin tinggi". Oleh sebab itu, dikemukakan Sondang P. Siagian (2002:1) bahwa "produktivitas suatu organiasasi harus selalu dapat diupayakan untuk terus ditingkatkan, terlepas dari tujuannya, misinya, jenisnya, strukturnya, dan ukurannya. Aksioma tersebut berlaku bagi semua jenis organisasi”. Jadi, sesuai dengan pendapat tersebut, tentunya termasuk di dalamnya organisasi pendidikan atau Sekolah Luar Biasa harus melakukan berbagai upaya guna meningkatkan efektivitas dan produktivitasnya, sehingga apa yang diharapkan dapat dicapai secara optimal.

Untuk melihat keberhasilan suatu sekolah tentu harus diukur dengan kriteria sebagaimana dikemukakan Sergiovanni dan Carver bahwa ada empat tujuan yaitu: Efektivitas produksi, efisiensi, kemampuan menyesuaikan diri (adaptiveness), dan kepuasan kerja, dapat digunakan sebagai kriteria untuk menentukan keberhasilan suatu penyelenggaraan sekolah. Efektivitas produksi, yang berarti menghasilkan sejumlah lulusan yang sesuai dengan tuntutan kurikulum yang berlaku.

$$
\text { Sekolah dipandang perlu }
$$
memberikan layanan kepada siswa yang memiliki tingkat kemampuan, kecerdasan, dan bakat yang luar biasa di atas standar rata-rata, dalam bentuk perlakuan pendidikan dan pengajaran, secara utuh dan optimal dalam waktu yang lebih cepat dibandingkan dengan sekolah reguler. Oleh sebab itu penyelenggaraan akselerasi pendidikan yang dimulai dari setiap jenjang pendidikan dapat terselenggara di sekolah-sekolah yang ada pada saat ini sebagai penampung dari aspirasi masyarakat yang diamanatkan melalui GBHN dan Undang-Undang Pendidikan Nasional yang berlaku dewasa ini. Hal ini juga berpengaruh pada fungsi dari sekolah luar biasa (SLB) tersebut, dimana sekolah luar biasa (SLB) dipandang dapat memberikan pelayanan kepada siswa yang memiliki kelainan fisik dan mental ini agar nantinya mereka dapat mengenyam pendidikan yang tidak saja didapat oleh anak-anak normal lainnya yang telah di landaskan oleh Undang-Undang Dasar 1945 dan Pancasila.

\section{METODE PENELITIAN}

Metode penelitian menggunakan metode historis dengan langkah-langkah heuristik, kritik sumber, interpretasi dan penulisan (Pengumpulan Data). Sumber Primer yang terdiri dari hasil wawancara sedangkan sumber skunder diperoleh melalui penelitian perpustakaan yang dilakukan dengan cara mencari bahanbahan yang berkaitan dengan latar belakang berdirinya SLB/A Negeri 
Denpasar. Teknik Penentuan Informan disusun melalui teknik Purposive Sampling. Teknik Wawancara dalam proses wawancara peneliti menggunakan wawancara mendalam dengan informasi berdasarkan pedoman wawancara dalam bentuk pertanyaan terbuka. Teknik Observasi, pengumpulan data dengan cara pengamatan dan pencatatan segala fenomena-fenomena yang terkait dengan masalah yang terkaji. Teknik studi dokumentasi dilakukan dengan cara pengumpulkan segala macam dokumen serta mengadakan pencatatan secara sistematis. Pengolahan Data dilakukan melalui kritik internal dan eksternal, dapat diperoleh data emik tentang latar belakang berdirinya Sekolah Luar Biasa Bagian A Negeri Denpasar dan system pendidikan di Sekolah Luar Biasa Bagian A Negeri Denpasar kemudian cross check dengan data yang didapatkan dari sumber buku dan wawancara lewat triangulasi data.

Interpretasi (Analisis Data) hasil evaluasi yang telah dilakukan dan mengacu pada hasil kritik data, maka data-data yang diperoleh baik melalui wawancara, observasi dan dokumentasi. Historiografi (Penulisan Sejarah), menggambarkan analisis dalam wujud uraian (rekonstruksi peristiwa dimasa lalu), yang dengan akurat memberikan unsur diakronis atau kronikel.

\section{PEMBAHASAN}

Sejarah Berdirinya Sekolah Luar Biasa Bagian A Negeri Denpasar
Sekolah sebagai sebuah lembaga pendidikan formal, khusunya di Indonesia, memiliki sejarah cukup panjang. Lingkungan keluarga dapat dikatakan sebagai titik awal berdirinya lembaga pendidikan. Hal ini ditegaskan oleh Hasbullah (2005:38) yang menyatakan, “lingkungan keluarga merupakan lingkungan pendidikan pertama, karena dalam keluarga inilah pertama kali mendapatkan bimbingan, tapi semuanya itu bersifat terbatas.

Sebagai lembaga pendidikan formal, sekolah juga merupakan tempat anak didik mendapatkan pelajaran yang diberikan oleh guru yang berijazah. Tujuannya untuk mempersiapkan anak didik menurut bakat dan kecakapan masing-masing agar mampu berdiri sendiri di dalam masyarakat. Sedangkan menurut badan pimpinannya, terdapat sekolah pemerintah, sekolah agama dan sekolah swasta.

Latar belakang berdirinya sekolah SLB/A Negeri Denpasar berawal dari keinginan Ida Ayu Putu Surayin untuk mendirikan sekolah untuk anak Tunanetra. dalam perjalanan panjang yayasan mengalami perkembangan. Yayasan mengambil kebijakan untuk mengajukan kepada departemen pendidikan dan kebudayaan untuk menegerikan Yayasan Dria Raba. Setelah disetujui maka SLB/A Dria Raba menjadi sekolah negeri dengan nama SLB/A Negeri Denpasar. Periodesasi sekolah dibagi menjadi dua yakni periode swasta dan 
periode negeri. Pada perubahan status SLB dari sekolah swasta menjadi sekolah negeri SLB mengalami perkembangan baik itu dari segi sarana prasarana, jumlah siswa, jumlah guru dan pegawai dan kepemimpinan sekolah.

Pada sistem pendidikan di Indonesia terdapat berbagai macam pendidikan dimana salah satunya pendidikan khusus. Bentuk dari pendidikan khusus seperti Pendidikan Luar Biasa (PLB) dengan bentuk sekolah yang bernama Sekolah Luar Biasa (SLB). Di Indonesia Sekolah Luar Biasa bagi anak yang berkebutuhan khusus baru mendapat perhatian setelah Undang-Undang Nomor 4 Tahun 1950 yang kemudian menjadi Undang-Undang Nomor 12 Tahun 1954 tentang pendidikan dan pengajaran bagi anak berkelainan dan wajib belajar bagi tunanetra, maka SLB yang diselenggarakan sangat pesat. Sekolah Luar Biasa secara umum dibebani tugas untuk melayani beberapa atau semua jenis ketunaan seperti tunanetra, tuna rungu, tuna grahita, tuna daksa, tuna laras, dan tuna ganda.

Salah satu Sekolah Luar Biasa yang terdapat di kota Denpasar yaitu Sekolah Luar Biasa bagian A Negeri Denpasar. Sekolah ini pada hakikatnya adalah sekolah yang diperuntukan kepada anakanak penderita cacat mata (tunanetra), agar mempunyai hak dan kesempatan yang sama untuk mengenyam pendidikan. Jika dilihat dari segi prestasi SLB/A Negeri Denpasar memiliki prestasi yang cukup membanggakan baik dari prestasi akademik maupun non akademik.

Prestasi tersebut menunjukkan SLB/A Negeri Denpasar sudah berhasil dalam mengayomi dan memberikan pelayanan pendidikan untuk anak tunanetra agar mereka bisa berprestasi dan bisa dipekerjakan dimana saja seperti anak normal lainnya. Hal ini sangat menarik untuk dikaji dalam karya tulis mengenai sistem pendidikan SLB/A $N$ Denpasar.

\section{Sistem Pendidikan Sekolah Luar Biasa Bagian A Negeri Denpasar}

Komponen pendidikan yang ada di SLB/A Negeri Denpasar meliputi: Kurikulum, proses pembelajaran, evaluasi, alat pendidikan, pendidik, peserta didik. Kurikulum yang digunakan SLB/A Negeri Denpasar adalah kurikulum KTSP. Jenjang pendidikan yang ada di SLB/A Negeri Denpasar antara lain TKLB, SDLB, SMPLB, SMALB. Kurikulum yang sudah ditetapkan oleh pemerintah pusat sesuai dengan peraturan undang-undang.

Proses pembelajaran, ada beberapa hal yang harus diperhatikan yakni kesiapan seorang guru, strategi mengajar, serta pendekatan pembelajaran yang tepat kepada siswa. Proses pembelajaran di SLB/A Negeri Denpasar tidak jauh berbeda dengan sekolah-sekolah pada umumnya. Akan tetapi dalam pembelajaran di dalam kelas siswa menggunakan buku berhuruf Braille, alat tulis bernama pen dan 
pencetak tulisan Braille bernama Riglet. Proses pembelajaran di SLB/A Negeri Denpasar berlangsung di dalam kelas dan di luar kelas.

Evaluasi pembelajaran, menurut Sudjana (2002:17-18) adalah suatu kegiatan yang di rencanakan dengan cermat yang merupakan bagian integral dari pendidikan, sehingga arah dan tujuan evaluasi harus sejalan dengan tujuan pendidikan. Evaluasi merupakan suatu tes, maka evaluasi dilaksanakan sepanjang kegiatan pendidikan. Jenis evaluasi yang diberikan SLB/A Negeri Denpasar kepada siswanya yang memiliki kekurangan pada penglihatan mereka memiliki kesamaan dengan sekolah Umum. Untuk mengukur kemampuan siswanya dari tingkat SDLB, SMPLB, SMALB guru biasa memberikan pertanyaan kepada siswa apakah mereka bisa menjawab atau tidak. Sekolah juga megadakan tes tengah semester, tes semester, tes akhir semester. Tes ini merupakan tes tertulis, tes lisan maupun praktek.

Alat pendidikan, yakni segala sesuatu yang dapat digunakan untuk mencapai tujuan pendidikan yang berfungsi untuk mempermudah atau mempercepat tercapainya tujuan pendidikan (Hasbullah, 2005:124). Salah satu alat pendidikan adalah sarana prasarana pendidikan. Saran prasarana yang tersedia meliputi ruang belajar, ruang perpustakaan dan ruang UKS, ruang guru, ruang kepala sekolah, ruang braille, ruang komputer, ruang keterampilan, ruang khusus/ ruang penyesuaian, ruang kesenian, ruang kepegawaian, ruang massage, aula, asrama putra, asrama putri, garasi, WC, kegiatan ekstrakurikuler.

Pendidik dan peserta didik, pendidik yaitu orang yang melaksanakan pendidikan sekaligus memberikan bermacam pengetahuan, norma, dan kecakapan. Pihak yang turut membentuk anak dan membantu menghumanisasikan anak. Guru-guru yang mengajar di SLB/A Negeri Denpasar mempunyai sebuah kewajiban mendidik peserta didik yang mempunyai ketunaan, khususnya tunanetra. Guru-guru SLB/A Negeri Denpasar tidak semua berasal dari tamatan SGPLB tapi ada dari tamatan non SGPLB, seperti tamatan UNDIKSHA, IHDN, IKIP Saraswati, dan IKIP PGRI Bali. Untuk peserta didik tentu saja berasal dari kalangan siswa yang mempunyai cacat khususnya tunanetra.

\section{SIMPULAN}

Sejarah berdirinya SLB/A Negeri Denpasar berawal dari berdirinya yayasan Dria Raba. Kemudian berkembang menjadi sekolah negeri dengan nama SLB/A Negeri Denpasar. Dan resmi menjadi sekolah SLB pertama di kota Denpasar sebagai tempat untuk memberikan pendidikan kepada anakanak cacat khususnya anak tunanetra. dari sistem pendidikan SLB/A Negeri pendidikan mempunyai fasilitas yang 
cukup memadaai jika ditinjau dari

kurikulum, proses pembelajaran,

evaluasi, alat pendidikan, sarana dan

prasarana, peserta didik dan guru.

\section{DAFTAR PUSTAKA}

Ahmadi, Abu dan Nur Uhbiyati. 2001. Ilmu Pendidikan. Semarang: Rineka Cipta.

Hasbullah. 2005. Dasar-dasar Ilmu Kependidikan. Jakarta: Raja Grafindo Persada.

Kuntowijoyo.1995. Pengantar Ilmu Sejarah. Yogyakarta: yayasan Bentang Budaya.

Moleong, Lexy.J. 2000. Metedologi Penelitian Kualitatif. Bandung: Remaja Rosdakarya.

SLB/ A Negeri Denpasar. 2008. Sejarah berdirinya SLB/A Negeri Denpasar. Denpasar. Dinas Pendidikan pemuda dan Olah Raga Provinsi Bali.

SLB/A Negeri Denpasar. 2010. Frofil Sekolah dan data administratisi. Denpasar: Dinas Pendidikan dan Olah Raga Provinsi Bali.

Sondang P. Siagian. 2002. Kiat meningkatkan produktivitas kerja, Jakarta: Rineka Cipta.

Suderadjat, Hari. 2005. Manajemen Peningkatan Mutu Berbasis Sekolah (MPMBS). Peningkatan Mutu Pendidikan Melalui Implementasi KBK. Bandung: Cipta Cekas Grafika.

Sudjana, Nana. 2002. Evaluasi Hasil Belajar dan Kontruksi Analisis. Bandung: Remaja Rosdkarya.

Syafaruddin. 2002. Manajemen Mutu Terpadu dalam Pendidikan, Konsep, Strategi dan Aplikasi. Jakarta: Grasindo. 